\title{
INFLAMAÇÃO: ENTRE A REGENERAÇÃO E A CICATRIZAÇÃO
}

\section{INFLAMMATION: BETWEEN REGENERATION AND HEALING}

\author{
Anelice Calixto Ruh ${ }^{1}$, Daniel Fernandes ${ }^{2}$, Roberto Ferreira Artoni ${ }^{3}$ e Giovani Marino \\ Favero $^{1}$
}

1-Programa de Pós-Graduação em Biologia Evolutiva, Laboratório Multidisciplinar de Pesquisas Básicas e Aplicada em Biologia e Saúde, Universidade Estadual de Ponta Grossa (UEPG). E-mail: <anelicecalixto@yahoo.com.br>; <gmfavero@yahoo.com.br>

2- Programa de Pós-Graduação em Ciências Farmacêuticas, Laboratório de Farmacologia Cardiovascular, UEPG. E-mail: < fernandesfarmaco@yahoo.com.br >

3 -Programa de Pós-Graduação em Biologia Evolutiva, Laboratório de Citogenética e Evolução,

Departamento de Biologia Estrutural, Molecular e Genética, UEPG. E-mail: <rfartoni@, gmail.com>

Data de recebimento: $12 / 03 / 2013$

Data da aprovação: 10/05/2013

\section{Resumo}

O reparo e a regeneração tissulares são processos complexos. O primeiro envolve vários tipos celulares e mediadores que regulam a cicatrização sendo dependente de uma série de fatores; a regeneração tissular, por sua vez, envolve a produção de blastema e remodelamento do tecido, restaurando as funções e integridade, sem formação de cicatriz. No processo evolutivo das espécies é fato que alguns organismos têm a capacidade de regeneração total e outros apenas de cicatrização. As salamandras, hidra, caranguejos, peixes, por exemplo, possuem a capacidade de regenerar por completo partes perdidas, já o homem tem esta capacidade limitada a alguns órgãos, ou parte deles, como fígado, epiderme e até certo ponto os nervos. Entretanto, vários estudos demonstram que o feto tem a capacidade de reparar tecidos através de um processo que se assemelha à verdadeira regeneração. Nestes processos, as células e citocinas do sistema imunológico são centrais para a reparação tecidual e cicatrização de feridas. O objetivo deste trabalho foi analisar, em uma visão evolutiva, aspectos que delineiam a fronteira entre a regeneração e a cicatrização a partir de um processo inflamatório lesivo inicial.

Palavras-chave: Evolução. Inflamação. Regeneração. Cicatrização.

\begin{abstract}
Tissue repair and regeneration are complex processes; the former involves several cell types and mediators which regulate healing and is dependent on a series of factors. The latter involves the production of blastema and tissue remodeling, restoring functions and integrity, without the formation of scars. In the evolutionary process of species, it can be observed that some organisms have total regeneration capability while others can only heal. Salamanders, hydras, crabs and fish, for example, can totally regenerate lost parts, whereas the human being has this capability limited to some organs, or parts of them, such as the liver, the epidermis and the nerves up to a certain point. In several studies, fetuses have been observed to repair tissues through a regeneration-like process.
\end{abstract}


The immunological system cells and cytokines are vital to tissue repair processes and wounds healing. The aim of this work was to analyze, from an evolutionary perspective, aspects which mark the borders between regeneration and healing following an initial lesion inflammatory process.

Keywords: Evolution. Inflammation. Regeneration. Healing.

\section{Introdução}

Após uma lesão, várias vias intracelulares e intercelulares são ativadas para que a integridade e homeostase do tecido sejam restauradas. Componentes celulares do sistema imune (neutrófilos, monócitos, linfócitos e células dendríticas), cascata de coagulação sanguínea e vias inflamatórias são mobilizadas levando a diferenciação, proliferação e migração celular na recuperação tecidual, e esta ativação ocorre por uma diversidade de mediadores inflamatórios (SINGER; CLARK, 1999; AARABI et al., 2007).

Os mediadores inflamatórios são liberados concomitante e sequencialmente e atuam amplificando e influenciando a evolução desta resposta. Destacam-se as moléculas vasoativas que atuam alterando o calibre dos vasos bem como aumentando a permeabilidade vascular. Além disso, há formação de fatores quimiotáticos que recrutam leucócitos do compartimento vascular até o tecido lesado. Esses leucócitos recrutados secretam outros mediadores inflamatórios que incrementam ou inibem a resposta inflamatória (RUBIN et al., 2006).

Existem várias citocinas envolvidas no processo inflamatório, como as interleucinas 1, $6,8,13,10$, que ativam células inflamatórias, e as citocinas como o fator de necrose tumoral (TNF) que ativa células endoteliais e tissulares (RUBIN et al., 2006; RIBEIRO et al., 2010). O fator transformador de crescimento beta (TGF- $\beta$ ), fatores de crescimento derivados de plaquetas (PDGF) e fatores de crescimento epidérmico (EGF) estimulam a proliferação de fibroblastos, secreção de matriz e induzem o recrutamento de leucócitos (AARABI et al., 2007).

Para a maioria das lesões, o reparo tecidual ocorre pela formação de um tecido fibroso, produzido principalmente por células como os fibroblastos, denominado cicatriz. Em alguns organismos eucarióticos a resposta à lesão é a regeneração total do tecido original. Os humanos têm essa capacidade de regeneração total durante o desenvolvimento prénatal, mas esta capacidade é perdida durante a vida adulta, um processo ainda pouco compreendido (Figura 1) (GURTNER et al., 2008). A regulação gênica durante $\mathrm{o}$ desenvolvimento embrionário e durante a vida deve ser um mecanismo a ser considerado na regeneração tecidual.

Figura 1: Esquema representando a divisão do processo de reparo tecidual e definição entre regeneração e cicatrização.

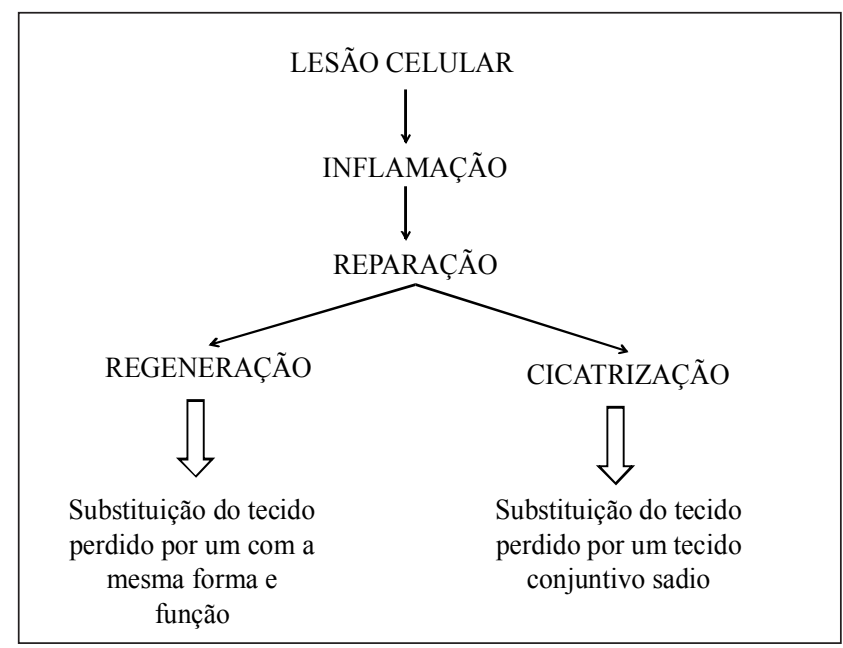

Fonte: Os Autores.

Ao longo da história foram sendo relatados casos de regeneração total de tecidos. Em 1712, um biólogo chamado de Réaumur (René-Antonie Ferchault de Réaumur [1683-1757]) apresentou uma ilustração detalhada da regeneração de parte de uma lagosta. Em 1740, um jovem professor suíço, Trembley Abraham (1710-1784), relatou um procedimento em que fragmentou um pólipo em duas partes, sendo que cada uma conseguiu se regenerar e formar um novo pólipo completo estruturalmente, dando assim início 
aos estudos de regeneração em metazoários (LOPES, 2010).

Em 1768, foram relatadas propriedades regenerativas em minhocas, caracóis, em patas, cauda e garra de salamandras. Em 1839, o cientista britânico Charles Darwin relata que fez um corte transversal em uma planária, partindo-a em duas partes quase iguais, notando que o animal havia se regenerado em aproximadamente quinze dias, formando dois indivíduos perfeitos de corpo e formato normal. Em 1901, chegou-se à definição de que regeneração é o processo biológico que consiste no reparo do tecido após uma lesão (LOPES, 2010).

Reddien, Alvarado (2004) citam que animais que conseguem regenerar partes perdidas possuem células estaminais (células-tronco) que têm o potencial de se diferenciarem em todos os tipos de tecidos e que fazem contínua substituição de células danificadas ou em envelhecimento. Leri et al. (2002) em seu estudo citam que células já diferenciadas podem proliferar em resposta a agressões teciduais. Um destes animais são as planárias, que possuem células indiferenciadas em grande quantidade de seu corpo e que migram para locais onde células estão morrendo ou para áreas em que houve alguma perda tecidual e se diferenciam em células específicas daquele tecido lesado (LOPES, 2010).

Salamandras também são capazes de regeneração de membros através da formação da blastema (uma massa de células de linhagem progenitoras restritas) após a perda do membro. Já os mamíferos têm uma limitada capacidade de regeneração. Entretanto, Seifert et al. (2012) em seu estudo com ratos africanos (Acomys) relatam que após furos nas orelhas os ratos sofreram regeneração total de folículos de cabelo, glândulas sebáceas, derme e cartilagem. Os autores ressaltam a importância de investigar fenômenos regenerativos fora de organismos usados como modelos convencionais de regeneração e sugerem que os mamíferos podem reter uma maior capacidade de regeneração do que se acredita. Entender os processos envolvidos na regeneração desta espécie pode ser útil na identificação de mecanismos para promover a regeneração em vez de fibrose e cicatrizes nos demais mamíferos.

O objetivo deste trabalho foi analisar, em uma visão evolutiva, aspectos que delineiam a fronteira entre a regeneraçao e a cicatrizaçao a partir de um processo inflamatório lesivo inicial.

\section{Regeneração}

Em 1901, Thomas Hunt Morgan escolheu para concluir seu livro "Regeneração" esta frase: "O processo regenerativo é um dos atributos fundamentais dos seres vivos". Não muito tempo atrás, esta observação teria sido considerada incorreta, já que a regeneração é geralmente associada a uns poucos organismos, como hidra, planárias e salamandras. No entanto, a descoberta de regeneração do fígado, em ratos e nos seres humanos, e as manifestações mais recentes de eventos regenerativos ocorrendo no sistema nervoso central validam a fundamentação de Morgan (ALVARADO, 2000).

A regeneração é a organização tecidual com a substituição das células mortas ou lesadas por novas células, idênticas às originais, promovendo a restituição total e a funcionalidade do tecido. A sequência de eventos que segue a um infarto do miocárdio é muito semelhante à que ocorre após uma lesão da medula espinhal ou uma queimadura. Portanto, em todos estes casos, ocorre a formação de uma cicatriz que leva à disfunção do tecido (MESCHER; NEFF, 2005).

A regeneração é um atributo de quase todos os seres vivos, mesmo que seja simples ou até completa de partes perdidas (membros, cauda, cabeça). Este é um processo altamente conservado ao longo da evolução. Se observarmos a escala evolutiva, percebemos que em todos os filos há organismos com capacidade de regeneração, embora ela seja variável entre os diferentes seres vivos (ALVARADO; TSONIS, 2006). Estas inferências ou sustentam que os genes responsáveis pela regeneração seriam ancestrais, ou teriam surgido em vários momentos da escala evolutiva, o que nos parece pouco provável.

Espécies com maior quantidade de tecidos diferenciados apresentam menor capacidade regenerativa. Mamíferos têm capacidade regenerativa limitada em comparação com outros organismos. $\mathrm{O}$ fígado é um dos poucos órgãos do corpo humano que pode regenerar-se em $70 \%$ sem formação de cicatriz (MESCHER; NEFF, 2005).

Sabe-se que alguns organismos, como a planária e as hidras, conservam populações de célulastronco durante sua vida e que são utilizadas para o processo de regeneração tecidual total. Diferentes das células-tronco "adultas" encontradas em tecidos humanos e mamíferos, que têm uma capacidade restrita para o desenvolvimento de diferentes tipos de células. Nas planárias as células-tronco estão 
distribuídas ao longo do seu corpo e quando um dano acontece estas células realizam reparos específicos (GARCIA, 2007).

Nos metazoários, o processo regenerativo se manifesta em diferentes graus de complexidade, mas geralmente se enquadram em duas categorias principais: morfaláxia e epimorfose. Regeneração morfoláxia é a restauração de estruturas danificadas não dirigida por proliferação celular, mas pela remodelação das partes restantes do corpo. A regeneração epimórfica requer a proliferação celular e depende da formação da blastema. A blastema é geralmente associada com a regeneração de estruturas muito complexas, tais como os membros, caudas e até mesmo cabeça. A formação de blastema ocorre em vários taxons que podem partilhar uma origem evolucionária comum e, portanto, um comum complemento genético. (ALVARADO, 2000).

Os platelmintos representam um ponto de transição no processo evolutivo. As planárias possuem características anatômicas, morfológicas e estruturais que poderiam ter sido plataformas para evolução dos tecidos e órgãos altamente especializados encontrados em organismos mais complexos (Figura 2) (NEWMARK; ALVARADO, 2002).

Figura 2: Esquema de Representação Evolutiva, destacando os platelmintos como ponto de transição evolutiva.

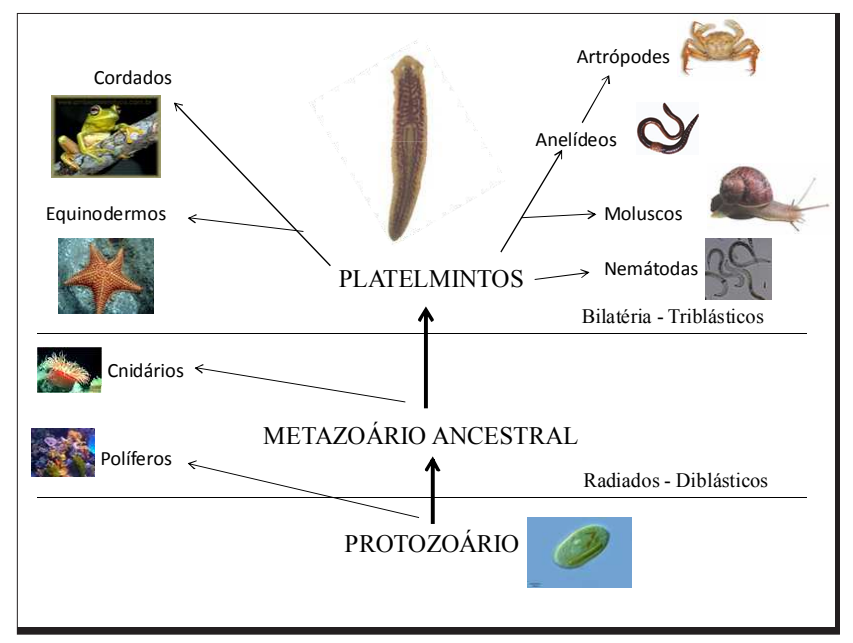

Fonte: Os Autores.

Quando comparada à cicatrização de feridas fetal em mamíferos, a cicatrização de feridas em adulto é uma resposta à lesão que sacrifica a regeneração do tecido original, para um tampão de matriz rápida, ou cicatriz, que protege o organismo contra infecções e trauma. Esta resposta é uma resposta adaptativa que o organismo adulto possa sobreviver (AARABI et al., 2007).

No nível molecular, o processo de regerenação tecidual apresenta muitos aspectos desconhecidos. Até agora, a maior parte dos estudos moleculares da regeneração tem usado planárias, que são modelos genéticos conhecidos, e se limita a estudos de modelos homólogos que já têm identificado seus genes reguladores do processo de reparação. Pouco se sabe sobre as semelhanças e diferenças que existem entre regeneração e embriogênese, de modo que métodos para estudar este problema são necessários (NEWMARK; ALVARADO, 2002).

Grandes sequências de DNA obtidas de planárias $D$. japonica e $S$. mediterranea estão sendo usadas para gerar microarranjos para a determinação da expressão do gene, perfis que definem os processos regenerativos e para identificação de genes específicos do sistema nervoso central. Estes estudos irão permitir a identificação de genes, a transcrição que é regulada durante as várias etapas regeneração, cicatrização de feridas e do padrão de proliferação. Tais moléculas podem ser estudadas em maior detalhe: examinando o padrão de expressão gênica e usando RNA para descobrir a inibição do gene que resulta em uma ruptura do processo regenerativo (NEWMARK; ALVARADO, 2002).

Antes que todo o potencial da planária como modelo possa ser realizada, deve-se descobrir quais as condições ideais para a cultivo (manter, expandir e diferenciar) in vitro de neoblastos (pequenas células indiferenciadas) (KNAKIEVICZ, 2007; NEWMARK; ALVARADO, 2002).

Um exemplo de regeneração entre os vertebrados é o peixe-zebra, que pode regenerar completamente seu coração após amputação de até $20 \%$ do ventrículo. Já os mamíferos não apresentam capacidade regenerativa do miocárdio, mas há uma iniciativa crescente para determinar se os cardiomiócitos existentes ou células progenitoras podem ser induzidos a provocar uma resposta regenerativa (POSS et al., 2002; JOPLING et al., 2010).

Para abordar diretamente a fonte de cardiomiócitos recém-formados durante a regeneração cardíaca do peixe-zebra, primeiro se estabeleceu uma 
estratégia genética para rastrear a linhagem de cardiomiócitos no peixe adulto. No estudo de Jopling et al. (2010), foi usado este sistema para mostrar que as células do miocárdio regeneradas são derivadas da proliferação de cardiomiócitos diferenciados. Além disso, mostrou-se que a proliferação de cardiomiócitos podem sofrer desdiferenciação limitada caracterizada pela "desmontagem" da sua estrutura sarcomérica e a expressão de genes reguladores da progressão do ciclo celular.

O peixe-zebra consegue regenerar o coração, e isso parece estar relacionado com uma menor resposta inflamatória que permite que este processo ocorra de forma equilibrada. Em humanos isso não acontece. Mesmo quando células-tronco são injetadas, elas acabam não conseguindo formar novas células cardíacas e parte disso pode ser consequência da inflamação que cria um ambiente inadequado para regeneração (SEGERS; LEE, 2008). Em muitos organismos, como mamíferos, a regeneração tecidual total não ocorre o que leva ao processo de cicatrização e, portanto, como dito acima, disfunção do tecido.

\section{Cicatrização}

A resposta a lesões em organismos complexos como mamíferos apresenta uma capacidade de reparo limitada (COSTA et al., 2009). Em mamíferos adultos, o processo de reparo ocorre pela substituição de células maduras, mas não de órgãos, e há formação de cicatriz, diferente do que é observado em invertebrados ou anfíbios (GOUREVITCH et al., 2003).

A cicatriz é caracterizada por fibroblastos e uma matriz extracelular desorganizada, formada principalmente por colágeno. Embriões e fetos podem reconstituir a pele após lesão sem a formação de tecido cicatricial. O fígado é um dos poucos órgãos de mamíferos adultos que pode regenerar até $70 \%$ por si só, sem a formação de cicatrizes.

Coelhos adultos são capazes de fechar furos na orelha, regenerando a pele, cabelo, vasos sanguíneos, nervos, músculos e cartilagem. Um caso semelhante de regeneração foi observado por acaso em ratos MRL, com reconstituição de lesão na orelha em 30 dias (GARCIA, 2007; COSTA et al., 2009).

Alguns estudos têm associado diferenças no processo de cicatrização com diferenças na atividade imunológica. Sugerem que a ocorrência de processos inflamatórios mais duradouros e a participação de linfócitos prejudicam a regeneração. A idade do organismo também influencia no tipo de cura da ferida, se por regeneração ou cicatrização. Feridas provocadas em mamíferos curam por regeneração, por diferença na composição da matriz extracelular, fatores de crescimento ou níveis de citocinas (COSTA et al., 2009).

A cicatrização constitui-se de três fases - fase inflamatória (0-2 dias), formação de novos tecidos (5-20 dias) e um estágio de remodelação (>21 dias) - as quais, juntas, envolvem a participação de muitos genes. A fase inflamatória se caracteriza por vasoconstrição, ativação de plaquetas que ativam a cascata de coagulação iniciando a formação de uma matriz de fibrina, permitindo a migração celular. Os neutrófilos são geralmente as primeiras células a infiltrar a lesão, destruindo micro-organismo invasores e, juntamente com os macrófagos, produzem fatores de crescimento que estimulam a angiogênese e a fibrinogênese. A formação de novos tecidos é caracterizada por proliferação e migração celular permitindo o início de cobertura da lesão. $\mathrm{Na}$ fase final, de remodelamento, ocorre uma transição de tecido de granulação em tecidos maduros com cicatriz (Figura 3) (CANHAMERO, 2009).

Este processo exige a participação de várias enzimas proteolíticas, incluindo metaloproteinases da matriz. Estudos demonstraram que as metaloproteinases têm um papel importante na desagregação da matriz provisória formada após o ferimento por quebrar vários componentes da matriz extracelular, incluindo colágeno do tipo IV, fibronectina, laminina, entactina e elastina, bem como a clarificação dos restos celulares e fibrilas que rodeiam o leito da ferida, ajudando a formação da blastema. A liberação de metaloproteinas estão envolvidas na remodelação e regeneração de partes do corpo após lesão em planárias (GOUREVITCH et al., 2003).

É difícil determinar os processos de sinalização que foram modificados durante a evolução dos vertebrados, o que resultou na incapacidade de regenerar estruturas complexas, como membros. Uma série de observações clássicas e recentes chama a atenção para o papel da regeneração dos nervos periféricos no resultado final do reparo de uma área perdida. A denervação prévia, ou na fase inicial da regeneração, após a amputação de um membro da salamandra, impede que um novo membro seja 
restaurado, enquanto a perda da função nervosa na fase tardia do processo não tem mais efeito sobre o resultado final. A supressão natural da regeneração axonal ocorre em mamíferos, e a inibição desse processo potencialmente favorece a recuperação funcional de tecidos agredidos. Por exemplo, oligodendrócitos são responsáveis pela formação da bainha de mielina dos axônios no sistema nervoso central e expressam inibidores da regeneração axonal associados à mielina, como Nogo-A. Anticorpos neutralizantes contra Nogo-A aumentam a recuperação funcional em graus variáveis nos modelos experimentais de lesão da medula espinhal. Em recente relato da inibição de Nogo-A em saguis (Callithix jacchus), um aumento da regeneração de fibras nervosas foi observado após lesão da medula espinhal. Ainda não está claro como esses achados podem ser relacionados à capacidade de regenerar estruturas não axonais. No entanto, eles demonstram que existem vias inibitórias da regeneração nervosa em mamíferos e que esse poderia ser o principal diferencial entre mamíferos e urodelos (SANTOS; ATHANAZIO, 2006).

Figura 3: Esquema demonstrando o processo de cicatrização tecidual.

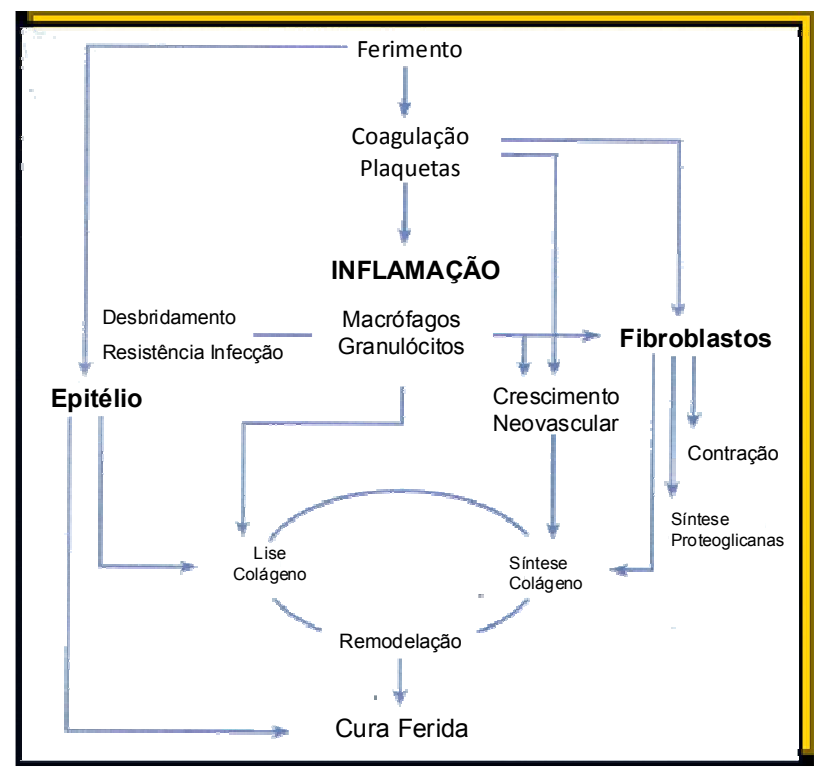

Fonte: Os Autores.

\section{Discussão}

A reparação e a regeneração se desenvolvem após respostas inflamatórias, sendo a inflamação por si só a resposta primária à lesão tissular. A inflamação aguda transitória pode sofrer resolução completa, com elementos parenquimatosos lesados localmente sendo regenerados sem formação importante do tecido cicatricial. Por exemplo, na recuperação de uma queimadura solar moderada, pequeno número de células inflamatórias agudas temporariamente acompanha a vasodilatação transitória abaixo da epiderme lesada pelo sol. Por outro lado, a inflamação aguda progressiva, com surgimento de inflamação com predomínio de macrófagos, é intrínseca à sequência de elaboração e reparação do colágeno (RUBIN et al., 2006).

Os locais de reparação variam na quantidade de destruição tissular local; por exemplo, uma incisão cirúrgica deixa pouco ou nenhum tecido desvitalizado; por outro lado necrose irregular e disseminada faz com que a inflamação aguda tenha que persistir para liquefazer o tecido necrótico, assim, o reparo não pode progredir até que as estruturas necróticas sejam removidas. Quanto mais tempo persiste o processo inflamatório mais tempo leva a cura tecidual levando à reparação por tecido fibrótico (cicatrização).

Alguns processos regenerativos podem ser pensados como uma recapitulação parcial da morfogênese embrionária a partir de células-tronco pluripotentes. Ao contrário das salamandras, os seres humanos não conseguem regenerar os membros, porém existem exemplos notáveis de processos regenerativos no osso, músculo esquelético e fígado. A medula óssea contém células-tronco, e o osso é um depósito protegido com capacidade de acesso imediato à circulação. As células-tronco endoteliais foram implicadas na angiogênese tissular e podem suplementar hiperplasia endotelial durante a regeneração de vasos sanguíneos.

Em um estudo sobre regeneração dos miócitos do peixe-zebra, Segers, Lee (2008) indicaram que células-tronco ou progenitoras não são significativamente envolvidas neste processo de regeneração. Então, para examinar a contribuição feita por cardiomiócitos diferenciados na regeneração cardíaca, foi realizada uma série de amputações experimentais em peixes-zebra adultos. Cerca de $20 \%$ do ventrículo foi removido, e a regeneração cardíaca foi posteriormente avaliada aos 7, 14 e 30 dias após a amputação. Aos 7 dias após a amputação, grande parte do tecido faltando tinha sido substituído por fibrina e coágulo de colágeno. Aos 14 dias após a amputação, os cardiomiócitos no interior do tecido foram uniformes com 
apenas um pequeno coágulo de fibrina restante. No geral, esse estudo mostrou que a regeneração do coração do peixe-zebra é impulsionada principalmente por cardiomiócitos pré-existentes, em vez de células progenitoras, como sugerido previamente.

O epitélio intestinal do humano renova-se constantemente e é substituído por células-tronco que residem nas criptas de Lieberkuhn. A regeneração hepática pode ocorrer por células-tronco quando os hepatócitos são lesados por hepatite viral ou por toxinas. E o fígado pode recrescer após hepatectomia parcial por resposta hiperplásica dos hepatócitos diferenciados maduros e, em sua maior parte, não envolve células-tronco (RUBIN et al., 2006; MICHALOPOULOS; DEFRANCES, 1997).

No estudo sobre a regeneração muscular esquelética, Pertille et al. (2012) relatam que ocorre um declínio da cicatrização de lesões musculo-esqueléticas com a idade. Eles estudaram também os efeitos do laser de baixa intensidade no processo de cicatrização de ratos idosos e concluíram que o laser mostrou eficácia na regeneração muscular em animais idosos somente por meio do seu efeito anti-inflamatório.

Os miócitos do coração humano são células diferenciadas, permanentes e indivisíveis. No entanto, estudos recentes fornecem evidências de regeneração mínima de miócitos a partir de célulastronco ou de reserva. A origem destas células ainda não está definida, ou seja, se elas residem no miocárdio ou se migram de locais desconhecidos após a lesão. A necrose do miocárdio cicatriza pela formação de tecido de granulação e consequente formação de tecido conjuntivo. Esta cicatrização resulta na perda de elementos contráteis e diminui a eficácia de contração do tecido fibrótico no miocárdio sobrevivente (RUBIN et al., 2006). Recentemente, um trabalho experimental em ratos mostrou que a modulação da resposta imunológica, com redução da resposta inflamatória pós-infarto, reduz a formação de fibroso no coração, melhorando sua funcionalidade e aumentando a sobrevida dos animais. Estes resultados confirmam a importante relação entre resposta imunoinflamatória e o processo de regeneração, além de mostrarem que a compreensão e manipulação deste processo representam importantes possibilidades terapêuticas.

As feridas fetais cicatrizam sem a formação de tecido conjuntivo embrionário. A falta de cicatriz é atribuída à epiderme embrionária de dupla camada (comparada com a derme estratificada do adulto), à ausência de TGF- $\beta$ na pele fetal e a uma maior quantidade de metaloproteinases quando comparadas à pele do adulto. Estas circunstâncias parecem ser fundamentais para promover uma resolução sem cicatriz. Na reepitelização do adulto, as células epiteliais avançam através da superfície da ferida, e no feto as células epiteliais são tracionadas para frente pela contração de fibras de actina (RUBIN et al., 2006).

Em seu estudo, Harty et al. (2002) relatam que a qualidade de cura do feto era atribuída inicialmente à solução aquosa estéril onde o feto fica inserido. Mas, pelo menos, dois tipos de experimentos indicam de outra forma. Marsupiais, como o gambá, nascem em um estágio de desenvolvimento equivalente ao final do primeiro trimestre do feto humano, e são criados na bolsa da mãe. Apesar da ausência de um ambiente estéril, feridas incisionais em gambás recém-nascidos curam com inflamação mínima e sem cicatrizes (HARTY et al. apud ARMSTRONG; FERGUSON, 1995). Tais experiências indicam que a cura da ferida não é uma função do ambiente pré-natal e sim o grau de diferenciação e a maturidade dos sistemas de outros órgãos são determinantes na eficiência da regeneração. A síntese de ácido hialurônico persiste por mais tempo no feto do que em feridas adultas, e isto pode moderar a resposta inflamatória e reduzir cicatrizes (HARTY et al. apud CHEN; ABATENGELO, 1999). Assim, o microambiente rico em ácido hialurônico pode ser responsável pela reduzida vascularização e menor nível de infiltração de macrófagos e inflamação em comparação com o tecido de granulação de feridas adultas.

Se não houvesse a capacidade de formar cicatrizes, a vida dos mamíferos seria quase impossível. Por outro lado, a formação de tecido fibroso em órgãos parenquimatosos modifica sua estrutura e não melhora sua função. Por exemplo, a lesão imunológica dos glomérulos renais resulta em sua substituição por uma cicatriz colagenosa e, se o processo for extenso, leva à insuficiência renal (RUBIN et al., 2006).

Assim, para auxiliar no processo de reparo tecidual, existem alguns recursos que podem ser utilizados e que cada vez mais vêm sendo estudados, como os medicamentos, processos mecânicos, cirúrgicos, etc. Em seu estudo com marsupiais, Armstrong 
e Ferguson (1995) citam que a adição exógena de TGF- $\beta$ em um modelo de ferida fetal leva a um aumento da fibrose nas feridas. Então neutralizar a ação do TGF- $\beta$ seria uma ação para redução da formação de fibrose tecidual.

\section{Conclusão}

O conhecimento sobre as características evolutivas que permeiam o limiar entre a regeneração e a cicatrização a partir de um processo inflamatório pode ser a chave para o aprimoramento do conhecimento e novos tratamentos em cicatrizes de órgão vitais. Embora os genes que regulam esses processos tenham surgido muito cedo na história evolutiva dos animais, os mecanismos que os regulam ainda é uma questão em aberto.

\section{Referências}

AARABI, S.; LONGAKER, M. T.; GURTNER, G. C. Hypertrophic scar formation following burns and trauma: new approaches to treatment. Plos. Med. n.4, p.234, 2007. Disponível em: <http://www.plosmedicine.org/article/ info\%3Adoi\%2F10.1371\%2Fjournal.pmed.0040234>. Acesso em: 13 novembro 2012.

ALVARADO, A. S. The case for Comparative Regeneration: Learning from simpler Organisms How to make New parts from Old. e-biomed, v.1. 2000. Disponível em: <http:// uuu.mindtel.com/ackbar/users/davew/eu-medics00/ healyourself/comparative.pdf $>$. Acesso em: 18 novembro 2012.

.; TSONIS, P.A. Bridging the generation gap: genetic insights from diverse animal models. Nature Reviews Genetics, v.7, p.873-884, 2006. Disponível em: <http:// www.nature.com/nrg/journal/v7/n11/full/nrg1923.html $>$. Acesso em: 13 novembro 2012.

ARMSTRONG, J. R.; FERGUSON, M. W. J. Ontogeny of the skin and the transition from scar-free to scarring phenotype during wound healing in the pouch young of a marsupial, Monodelphis domestica. Dev. Biol. n.169, May p.242-60, 1995. Disponível em: <http://www.ncbi.nlm.nih. gov/pubmed/7750642>. Acesso em: 21 novembro 2012.

CANHAMERO, T. A. Estudo dos mecanismos genéticos e celulares durante a fase inflamatória do processo de regeneração tecidual em animais selecionados geneticamente para máxima resposta inflamatória aguda homozigotos para os alelos $\mathrm{R}$ ou $\mathrm{S}$ do gene SIc11a1. Dissertação. Programa de pós-graduação em imunologia do instituto de ciências biomédicas da Universidade de São Paulo. 2009. Disponível em: <http://www.teses.usp. br/teses/disponiveis/42/42133/tde-03022010-093331/pt-br. php>. Acesso em: 20 novembro 2012.

COSTA, R. A.; SOUZA, R.; AZEVEDO, G. M.; VAZ, N. M.; CARVALHO, C. R. Effects of strain and age on ear wound healing and regeneration in mice. Braz J Med Biol Res. , v.42, n.12, p.1143-1149, Dec. 2009. Disponível em: $<$ http://www.scielo.br/pdf/bjmbr/ 2009nahead/7742.pdf >. Acesso em: 20 novembro 2012.

GARCIA, N. M. R. Proliferação de células-tronco em planárias submetidas a radiação laser nos estágios iniciais de regeneração tecidual. Dissertação apresentada ao programa de Pós-graduação em Engenharia Biomédica do Instituto de pesquisa e Desenvolvimento da Universidade do Vale do Paraíba, São José dos Campos, 2007. Disponível em: $<$ http://biblioteca.univap.br/dados/00 0002/00000264. pdf $>$. Acesso em: 07 novembro 2012.

GARCIA, L. V. Estudo de mecanismos regulatórios envolvidos na regeneração tecidual em linhagens de camundongos geneticamente selecionados para máxima ou mínima resposta inflamatória aguda. Dissertação. Programa de pós-graduação em imunologia do instituto de ciências biomédicas da Universidade de São Paulo. 2010. Disponível em: <https://uspdigital.usp.br/tycho/ producaoacademica/icb/.../ BE2-0.html>. Acesso em: 20 novembro 2012.

GOUREVITCH, D.; CLARK, L.; CHEN, P.; SEITZ, A.; SAMUlEWICZ, J.; HEBER-KATZ, E. Matrix metalloproteinase activity correlates with blastema formation in the regenerating MRL mouse ear hole model. Developmental Dynamics. n.223, p. 377-87, 2003. Disponível em:<http://onlinelibrary.wiley.com/ doi/10.1002/dvdy.10243/pdf > Acesso em: 20 nov. 2012.

GUYTON, A. C. Tratado de fisiologia médica. 9.ed. Rio de Janeiro: Guanabara Koogan, 1997. ap. 33, p. 317-323.

GURTNER, G. C.; WERNER, S.; BARRANDON, Y.; LONGAKER, M. T. Wound repair and regeneration. NATURE. v. 453, 2008. Disponível em: <http://www. annual reviews.org/doi/abs/10.1146/annurev.med.58.0824 05.095329? journalCode $=\mathrm{med}>$. Acesso em: 12 novembro 2012.

HARTY, M.; NEFF, A. W.; KING, M. W.; MESCHER, A. L. Regenerations or Scarring: An Immunologic Perspective. Developmental Dynamics. n. 226, p. 268279, 2003. Disponível em: <http://www.ncbi.nlm.nih.gov/ pubmed/12557205 >. Acesso em: 12 novembro 2012.

JOPLING, C.; SLEEP, E.; RAYA, M.; MARTÍ, M.; RAYA, A.; BELMONTE, J. C. I. Zebrafish heart regeneration occurs by cardiomyocyte dedifferentiation and proliferation. Nature, v. 464, p.606-609, 2010. Disponível em: <http:// www.nature.com/nature/journal/ v464/n7288/full/ nature08899.html>. Acesso em: 12 nov. 2012. 
KNAKIEVICZ, T. Carcacterização da biologia de populações de planária do gênero Girardia nativas do Rio Grande do Sul. Dissertação. Universidade Federal do Rio Grande do Sul. Programa de Pós-Graduação em Biologia Celular e Molecular. 2007. Disponível em: <http://www. lume.ufrgs.br/bitstream/handle/10183/24078/000741287. pdf ?sequence $=>$. Acesso em: 19 novembro 2012.

LERI, A.; KAJSTURA, J.; ANVERSA, P. Myocyte proliferation and ventricular remodeling. J. Card. Fail., n.8, p. 518-25, 2002. Disponível em: <http://www.ncbi.nlm.nih. gov/ pubmed/12555 168>. Acesso em: 13 novembro 2012.

LOPES, D. H. Controle do processo de regeneração celular em Planárias Schmidtea mediterranea pelo Método double-stranded RNA. Investigação, n.10, p. 49-53, 2010. Disponível em: <http://publicacoes.unifran.br/ index.php/investigação/article/viewFile /304/244>. Acesso em: 8 novembro 2012 .

MESCHER, A. L.; NEFF, A. W. Regenerative capacity and the developing immune system. Adv. Biochem. Eng. Biotechnol., n.93, p.39-66, 2005. Disponível em: $<$ http:// link.springer.com/ chapter/10.1007\%2Fb99966?LI=true\#>. Acesso em: 13 novembro 2012.

MiCHAlOPOUlOS, G. K.; DEFRANCES, M. C. Liver regeneration. Science, n. 276, p. 60-66, 1997. Disponível em: $<$ http://www.ncbi.nlm.nih.gov/pmc/articles/PMC2701258 / pdf/nihms 85379.pdf>. Acesso em: 18 novembro 2012.

NEWMARK, P. A.; ALVARADO, A. S. Not your father's planarian: a classic model enters the era of functional genomics. Nature Reviews Genetics, v.3, p. 210-219, 2002. Disponível em: $<$ http://people.physics.illinois.edu/ Selvin/PRS/498IBR/Phil.NatureRev.2002.pdf>. Acesso em: 13 novembro 2012.

PERTILle, A.; MACEDO, A. B.; OLIVEIRA, C. P. V. Avaliação da regeneração muscular em animais idosos após tratamento com laser de baixa intensidade. Revista Brasileira de Fisioterapia. 2012. Disponível em: $<$ http:// www.scielo.br/pdf/rbfis/2012nahead/pt_aop050_12_1311. pdf $>$. Acesso em: 20 novembro 2012.

POSS, K. D.; WILSON, L. G.; KEATING, M. T. Heart regeneration in zebrafish. Science. n. 298 (5601), p. 218890, 2002. Disponível em:<http://www.ncbi.nlm.nih.gov/ pmc/articles/PMC2846535/>. Acesso em: 12 novembro 2012.

REDDIEN, P. W.; ALAVARADO, A. S. Fundamentals of planarian regeneration. Annu. Rev. Cell Dev. Biol. n. 20, p. 725-57, 2004. Disponível em:< http://www.sdbonline. org/2012 Course/annurev_cellbio.pdf $>$. Acesso em: 13 novembro 2012.

RIBEIRO, B. P.; PEREIRA, W. S.; SOUSA, A. I. P.; GUERRA, R. N. M.; NASCIMENTO, F. R. F. Alteração no perfil bioquímico induzido por reação inflamatória granulomatosa em camundondos. Rev. Ciênc. Saúde, São Luís, v.12, n.1, p. 73-79, jan./jun.2010. Disponível em:<http://gurupi.ufma.br/index.php/rcisaude/article/ viewFile/969/646\#page=73>. Acesso em: 09 nov. 2012 .

RUBIN, E.; GORSTEIN, F.; RUBIN, R.; SCHWARTING, R.; STRAYER, D.; Patologia. bases clínicopatológicas da Medicina. 4 ed. Rio de Janeiro: Guanabara Koogan, 2006.

SANTOS, A. C.; ATHANAZIO, D. A. Estratégias de regeneração em anfíbios urodelos. R. Ci. méd. biol., Salvador, v. 5, n. 2, p. 160-170, mai./ago. 2006. Disponivel em: $\quad$ www.portalseer.ufba.br/index.php/cmbio/articlel download/.../3011>. Acesso em: 20 outubro 2012.

SEIFERT, A. W.; KIAMA, S. G.; SEIFERT, M. G.; GOHEEN, J. R.; PALMER, T. M.; MADEN, M. Skin shedding and tissue regeneration in African spiny mice (Acomys). Nature. v. 489 n.7417, p.561-5, 2012. Disponível em: <http://www.nature.com/nature/ journal/v489/ n7417/ full/nature11499.html>. Acesso em: 12 novembro 2012.

SEGERS, V. F. M.; LEE, R. T. Stem-cell therapy for cardiac disease. Nature. v. 451, n.7181, p. 937-42, 2008. Disponível em:<http://www.nature.com/nature/journal/v451/n7181/ full/nature06800.html>. Acesso em: 12 novembro 2012.

SINGER, A. J.; CLARK R. A. Cutaneous wound healing. The New England Journal of Medicine, n.341, p.738-46, 1999. Disponível em: <http://www.sassit.co.za/Journals /Trauma/Head\%20injuries/Cutaneous\%20wound $\% 20$ healing\%20review\%20NEJM.pdf>. Acesso em: 27 janeiro 2012. 